\title{
Measurement of tracheobronchial clearance after sauna in subjects with chronic bronchitis
}

\author{
Michel van Hengstum, Jan Festen, Frans Corstens
}

\begin{abstract}
The effect of sauna on tracheobronchial clearance was studied in five male patients with chronic bronchitis by a radioaerosol technique. No enhancement of tracheobronchial clearance could be detected.
\end{abstract}

Sauna has been shown to cause significant though transient improvement in $\mathrm{FEV}_{1}$ in patients with chronic airflow obstruction. ${ }^{1}$ It is also thought to help subjects to acclimatise to rapid temperature changes and to have a bronchodilator effect. The rehabilitation programme for patients with pulmonary diseases in the university lung centre at Nijmegen included the regular use of sauna, and many patients with chronic bronchitis and abundant sputum production indicated that expectoration seemed to be improved during or after it.

As sauna might provide an alternative to physiotherapy as an aid to the clearance of excessive bronchial secretions, a study was performed to assess its effect on tracheobronchial clearance in patients with chronic bronchitis.

\section{Methods}

Five men with chronic bronchitis (MRC criteria $^{2}$ ) took part in the study. Their mean (SD) age was $52(12)$ years, their mean forced expiratory volume in one second $\left(\mathrm{FEV}_{1}\right) 69 \%$ $(9 \%)$ predicted, and their mean vital capacity $92 \%(14 \%)$ predicted.

Tracheobronchial clearance was measured by a radioaerosol technique. ${ }^{3}$ An aerosol of 5 $\mu \mathrm{m}$ polystyrene particles labelled with technetium-99m was inhaled under standardised conditions. Intrathoracic radioactivity was then measured at regular intervals by two scintillation detectors. The sum of the radioactivity count rates from the two detectors was corrected for background activity, physical decay of the radionuclide, and 24 hour retention. ${ }^{4} \mathrm{~A}$ tracheobronchial retention curve was obtained by plotting percentage retention against time. A mean tracheobronchial retention curve was produced from the individual retention curves, interpolated percentages at 20 minute intervals being used.

Tracheobronchial clearance was measured on two separate days in a randomised crossover fashion. On one day the patient took part in a standardised sauna programme, going into the sauna for one and a half hours immediately after the first measurement. No measurements were performed during this period. After com- pletion of the sauna tracheobronchial clearance was measured for about two hours. Measurements on the day with no sauna provided a control. $T_{0}$ was defined as the time of the first measurement, from 10 to 30 minutes after inhalation of the radioaerosol. On the control day $T_{0}$ was the same length of time after the inhalation as on the sauna day for each patient, to minimise the intrasubject variability in the number of counts at the beginning of the retention curve. Tracheobronchial retention is expressed as the percentage of the corrected activity measured at $T_{0}$.

The sauna programme included two identical cycles. Each cycle began with a hot shower followed by 10 minutes in the hot cabin (air temperature about $90^{\circ} \mathrm{C}$, relative humidity about $15 \%$ ). The subject then had a cold

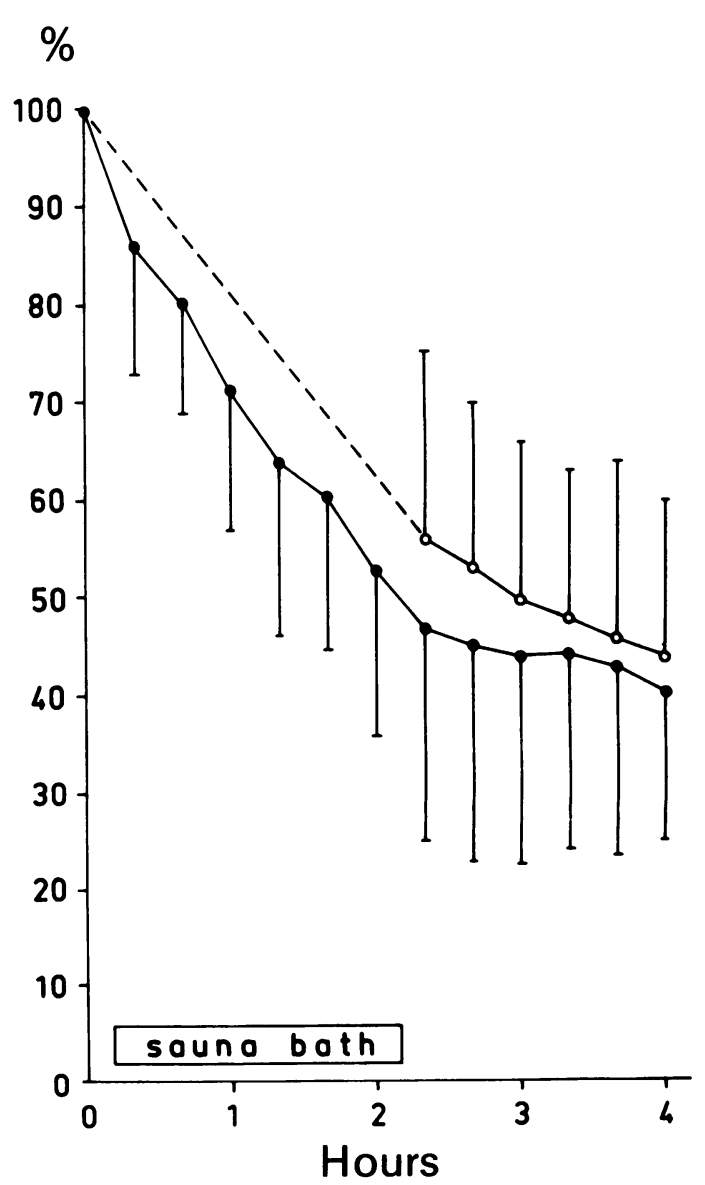

Tracheobronchial retention after inhalation of a radiolabelled aerosol before and after sauna (O) and during control measurements (O) in five patients with chronic bronchitis: mean (SD) proportions of baseline $\left(T_{0}\right)$ corrected radiation counts. 
shower followed by three immersions in cold water and a rest of about 15 minutes.

Student's paired $t$ test was used to assess the significance of any differences observed.

\section{Results}

The mean (SD) 24 hour retention of labelled particles was $56 \%(19.8 \%)$ after sauna and $47 \cdot 2 \%(21.6 \%)$ on the control day. No significant differences were observed between the two series of measurements $(95 \%$ confidence limits $-16 \cdot 9 \%,+34 \cdot 5 \%$ )-see figure.

\section{Discussion}

Inhalation of nebulised saline has been shown to enhance mucociliary clearance and give a greater sputum yield. ${ }^{56}$ The hypothesis has been put forward that hydration of the periciliary fluid is necessary for optimal mucociliary clearance. ${ }^{7}$ Although humidification seems beneficial and parts of the sauna course take place in a humid atmosphere, the air in the sauna cabin is very dry. This could explain the lack of enhancement of tracheobronchial clearance. The improved expectoration reported by patients could result from the production of more saliva. We conclude that sauna cannot be substituted for chest physiotherapy.

1 Cox NJM, Oostendorp GM, Folgering HThM Herwaarden CLA van. Sauna transiently improves pulmonary function in patients with obstructive lung disease. Arch Phys Med Rehab 1990;9:911-3.

2 Medical Research Council. Definition and classification of chronic bronchitis for clinical and epidemiological purposes. Lancet 1965; i:775-9.

3 van Hengstum $M$, Festen J, Buijs W, van den Broek W, Corstens F. Variability of tracheobronchial clearance in healthy non-smoking subjects. Respiration 1988;56: 4-102.

4 Pavia D, Bateman JRM, Clarke SW. Deposition and clearance of inhaled particles. Bull Physiol Respir 1980; 16:335-66.

5 Pavia D, Thomson MM, Clarke SW. Enhanced clearance of secretions from the human lung after the administration of hypertonic saline aerosol. Am Rev Physiol 1978;117: 1199-203.

6 Sutton PP, Gemmelt HG, Inner N, Davidson J, Smith FW, Legge JS, et al. Use of nebulised saline and nebulised terbutaline as an adjunct to chest physiotherapy. Thorax 1988;43:57-60.

7 Litt M. Mucus rheology. Arch Intern Med 1970;126:417-23. 